\title{
WHAT GOVERNANCE AND REGULATIONS FOR THE INTERNET? ETHICAL ISSUES
}

Jacques Berleur and Yves Poullet ${ }^{1}$

Facultés Universitaires Notre-Dame de la Paix, Namur, Belgium, jberleur@info.fundp.ac.be yves.poullet@fundp.ac.be

Key words: Technical regulation, IETF, W3C, ICANN, Self-regulation, Legal regulation, Ethics

\section{INTRODUCTION}

If Vinton Cerf, one of the fathers of the Internet and the founder of the Internet Society (ISOC) is to be believed, then "As we move into a new century marked by the Internet's ubiquitous presence, we must dedicate ourselves to keeping the network unrestricted, unfettered, and unregulated." [Cerf, 1999] Few still share such radical views. Philippe Quéau, at the time Director of the Information and Informatics Division of UNESCO, specifically hinted at such an intention: "The structural imbalances in the world infrastructure of the Internet, the profound inequalities of access to information, the trans-national oligopolies controlling the planet's info-

1 A shorter version of this text has been published in a French monthly journal, ETVDES, tome 397, Paris, 2002, Assas-Editions http://perso.wanadoo.fr/assas-editions/etudes.htm The text has been updated according to the discussions at the worldwide level, in particular at the occasion of the World Summit on the Information Society (Geneva 2003.

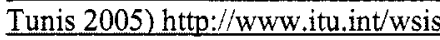


structure are equally the area of concern for the regulator. A new form of regulation or of world 'governance' should be conceived, from the perspective of global ethics, for the service of equality and human development." [Quéau, 1999] Others have thought about a Lex Informatica of technical Internet regulation, based on the model of the old Lex Mercatoria [Reidenberg, 1998]. The question of Internet regulation and governance is without any doubt, technical, political and ethical.

The Declaration of Principles of the first phase of the World Summit on the Information Society (Geneva, December 2003) insisted on the fact that "the governance of the Internet should constitute a core issue of the Information Society agenda", and having been unable to reach a consensus before the Summit of 2003, "the Secretary-General of the United Nations was asked to set up a working group on Internet governance, in an open and inclusive process that ensures a mechanism for the full and active participation of governments, the private sector and civil society from both developing and developed countries, involving relevant intergovernmental and international organizations and forums, to investigate and make proposals for action, as appropriate, on the governance of Internet by 2005." [WSIS, 2003] The same Declaration of Principles asked for ethical insistence.

We can no longer say today - if ever we could - that we lack regulation because notably the Internet escapes the territorial sovereignty. There is, without doubt, a calling into question of the traditional regulatory framework, but its exact impact remains to be seen. Some stress the prevalence of technical regulation and self-regulation over traditional public regulation. Our intention is to analyse these three sources of regulation - or of governance - and to propose a critical reading of the case for each one to be the only source of regulation of the Internet.

\section{TECHNICAL REGULATIONS}

Technical regulations are clearly apparent on the Internet. We refer to three, relating to three organizations: the Internet Engineering Task Force (IETF) and therefore the Internet Society (ISOC), the World Wide Web Consortium (W3C), and the Internet Corporation for Assigned Names and Numbers (ICANN) [Regulating the Internet, 2000], [Brousseau, 2001], [Simonelis, 2005]. 


\subsection{The Internet Engineering Task Force (IETF)}

The IETF is an organization that dates back to 1986 and whose essential work is still today to ensure the standards and norms that ensure the full interoperability of the networks. It is an independent organization, that has been supported by the ISOC, and which has had some setbacks with the international standards organizations, such as the International Organization for Standardization (ISO) and the International Telecommunication Union (ITU), both agencies of the UN. The clashes took place notably between 1992 and 1994, at the moment where the ISO was looking to replace TCP/IP (Transmission Control Protocol / Internet Protocol), which was worked out from the beginning of the ARPANET network by the United States Department of Defense (1969) and which ensured the interoperability of today's networks. The ISO and the ITU appeared not to be prepared, in matters of such importance, to allow the practices of an institution with such little institutional organization, working from the grass roots and with ostensibly, although little explained, consensus methods of decision-making. Since then the IETF seems to have continued along its path in relative peace and kept its normative prerogatives, while making it known that it does not see an official delegation close to other organisms of standardization as an adequate solution. [On the Internet, 2001]

The subjects dealt with by the IETF are very technical, among others currently being examined is version 6 of the Internet Protocol (IPv6), which is under construction, but also encoding and transport, of models of impression protocol semantics and so on. Every question relating to the working of the Internet and needing standardization, whether a question of transport, routing, security, service for users, or so on, passes through the IETF. IETF has been often considered as "the protocol engineering and development arm of the Internet." Since the beginning of networks (March April, 1969) until early July 2005, some 4130 Requests for Comments (RfC: see infra) have been drafted. [RfC, 2005]

The organization remains quite complex; it must be mentioned that it relies on some 2000 volunteers divided into some 130 Working Groups on subjects decided upon by a Steering Committee, the Internet Engineering Steering Group (IESG). We also note the Internet Research Task Force (IRTF) that organizes these research groups and the Internet Architecture Board (IAB), one of the committees nominated by the IETF to assist in its management and to play a formal interfacing role with the Internet Society, the ISOC. 
The standardization or normalisation process developed by the IETF is reported in the Requests for comments ( $\mathrm{RfCs}$ ). It has little to do with "requesting comments" as the name suggests, but rather with the notes that report the exchanges on different aspects of communication, the network protocols, the programmes, the underlying concepts; these also include reports about meetings, opinions, and even some humorous notes. More fundamentally, these RfCs, all of which are published on the IEFT site, consist of all the specification protocol documents or Guidelines of the Internet. From 1969 until his death in 1998, this work was scrupulously carried out by one man, Jonathan Postel, the legendary figure to whom the Internet domain names are sometimes attributed. Today (June 2005), the RfCs number more than 4000 and the work of J. Postel is carried on by the person he trained, Joyce Reynolds.

In the final analysis however, what does the IETF consist of? As we have mentioned, it is a de facto organization, independent, and without a juridical presence; it is composed of Internet services providers, of users of the Internet, software and hardware vendors, researchers, network operators, academics, and all other interested parties. The volunteers or the people sent by, and at the cost of, their organization meet regularly, even if until three times one week per year. This community has functioned until now with the method of "rough consensus", more than a simple majority, but not unanimity, as The Economist noted [Regulating the Internet, 2000]. What does the future hold for it? The same Economist called to mind the 'benevolent dictators' that created the consensus doubtless at the expense of more democratic processes where the more societal outcomes of the technical choices could have been discussed. Doubtless it comes down to the "charisma of the pioneers", such as Vint Cerf and Jonathan Postel!

\subsection{The World Wide Web Consortium (W3C)}

The W3C was also born from the charisma of one person, Tim BernersLee. He is the man who created the first server, the first browser; the man who in 1994 created the World Wide Web (WWW).

The W3C was founded in the same year as the WWW at the Massachusetts Institute of Technology (Cambridge USA) in cooperation with CERN (Geneva), and is also a regulatory organ of the web. Until today it has produced some 90 'Recommendations' (technical specifications or set of guidelines) relating to the web's infrastructure, notably in the field of the architecture of the web (and its associated technologies), document formatting (formats and languages for presenting user information), the tools 
that favour every form of interaction, that develop accessibility for everyone, and every question of social, legal or general political relevance. It is in this way for example that the $\mathrm{W} 3 \mathrm{C}$ is progressively transforming the initial web (HTML - the lingua franca of the first web -, URLs, HTTP, and so on) into a web for tomorrow, built on the solid foundations provided by XML (Extensible Mark-up Language). As L. Lessig says, technical architecture may correspond to different types of regulation [Lessig, 1999, 30]. Everyone agrees that with the philosophy of the $\mathrm{W} 3 \mathrm{C}$, openness and decentralization, has been incorporated into the technical norms of the WWW to the point that today they are defined as its characteristics. We also note, among the proposals of W3C, the recommendation of the PICS (Platform for Internet Content Selection), standard for filtering notably illicit or harmful content on the Internet [PICS].

The $\mathrm{W} 3 \mathrm{C}$ comprises of 500 member organizations, product vendors and technological services, content suppliers, utility companies, research laboratories, standardizing organizations, governmental representatives and so on. Anyone signing the membership agreement may become a member of the W3C, but a 'full member' pays a subscription fee of US $\$ 1000$ to 77000 - on the average 50000 -, while an affiliate member pays only 5000 . It is an open organization, without a juridical statute, housed in turn by one of three host research institutions: INRIA (France), the Massachusetts Institute of Technology (USA) and Keio University (Japan).

\subsection{The Internet Corporation for Assigned Names and Numbers (ICANN)}

Last born of the Internet regulatory organizations that we intend mentioned is the Internet Corporation for Assigned Names and Numbers (ICANN). The birth in 1998 is here not the fruit of any individual charisma, but rather of the liberal ideology of technicians and Internet engineers that brought the American Department of Commerce to get rid of the attribution of TCP/IP addresses and domain names attribution. ICANN is an organization, which, globally and in a centralized way, runs the address system of the web. This centralization brings with it a management system that can differ according to the registration office where the national geographic domain names are attributed. Those that have followed the creation of ICANN know the themes that have progressively appeared. ICANN has been mentioned as an example of the global Internet governance, perhaps reducing it to its technical dimension, and of selfregulation by a "non-profit, private sector corporation", as said on its web site. The capacity of ICANN has been evoked to delete addresses, but 
without doubt it is more precisely the sign of a new system of governance and Internet regulation that has really been in question: an American federal department gave up one of its prerogatives to transfer it to an organization made by governmental and private representatives at a world level.

The day after the ICANN meeting in Stockholm at the beginning of June 2001, however, some spoilsports broke the beautiful unanimity. The roundtables held during the world ISOC conference (INET 2001) that followed this meeting, where the critics of the electoral procedures, notably that of 'ICANN at large', that is to say ensuring the representation of users flew from all sides: nine seats for 400 million Internet users! Who voted? The users? Those that are affected by the networks? The Internet, a public space, more and more sponsored by private interests! And so on. That which incited Carl Bildt, former Prime Minister of Sweden, given a mission by ICANN, to plead for a different representation than representative democracy! In short, as a number of editorialists have underlined, 'ICANN at large' could well have been restructured, and the ISOC would be approached. Besides the reasons for its representativeness, the efficacy of ICANN was contested, although in fact, it was all about an organization with about twelve people and an annual budget of USS 4.3 million.

On February 24, 2002, the ICANN President, Stuart Lynn, published his first annual report: ICANN - The Case for Reform - proposing a better balance between private and public, and a better participation of the public, declaring the failure of a pure private structure, and proposing new ways of representation. An "At Large Advisory Committee (ALAC)" was appointed by the ICANN Board, which made proposals of new Bylaws adopted at the Shanghai October 2002 meeting. A totally new ICANN structure has been proposed where the "ICANN At Large" seems to be on the same stand as other Advisory Committees such as the Government Advisory Committee (GAC) [ICANN, 2002].

A new charter of the Board has been designed in 2002, which shows that the majority of representatives comes still from "technical supporting organizations", and "technical advisory committees", whereas, out of the president, 14 voting directors and 6 non voting representatives, the GAC has only one seat and the capacity of being a member of the "nominating committee."

The ICANN saga is still going on, $\ldots$ and recently the Internet Governance Project issued some main criticisms, among which the dissatisfaction of the GAC, where governments have only advisory powers, 
and its legitimacy [Klein \& Mueller, 2005]. The ICANN position has been also questioned by the Working Group on the Internet Governance, set up by the Geneva Summit on the Information Society that we mentioned [WGIG, 2005], and it seems today that the US are not to give up to their control of the Net's root to ICANN "The U.S. government will continue to maintain 'oversight' of ICANN and prevent its 'focus' from straying from technical coordination." [McCullagh, 2005]

Some questions regarding ethical aspects arise from this brief description of the technical regulations. What is the degree of transparency and clarity of information about such complex subjects? What is at stake, for example, in the new IPv6 protocol? It should be pointed out in this case that version 4, currently in use, was developed to support 4 billion ( $410^{9}$ ) addresses whose two tiers are still today reserved for North America, that is to say $5 \%$ of the world population. The new protocol should support $3.410^{38}$ addresses (340 trillion trillion trillion trillion) and allow the convergence of all communication technologies (current IP addresses, generalization of IP telephony, electronic directories, and so on). Resistances emerge particularly in US Business milieu because of the rather weak support of service providers and networks administrators and because of the transfer costs and of the migration from IPv4 towards IPv6, etc. In summary, a new Y2K could be at the horizon [Lawton, 2001].

Underneath this purely technical character, there are problems of privacy that have not been resolved and which the IETF appears to be currently making proposals on. There are also political decisions about future lifestyles, particularly about more and more intrusive - or ubiquitous as said today - computing, taken outside national and international authorities.

There are only 13 main root servers in the world: 10 in the United States, 2 in Europe (London and Stockholm) and one in Asia. Does this state of affairs contradict the international character of the Internet?

What is the legitimacy of bodies that are given the right of technical regulation apart from all recognized supervision, by the state or by international public bodies? What will happen when China demands that the standards that it developed itself be taken into account by the quasi strictly American standards bodies? And so on.

Those who should not yet been convinced of the technical regulators position, should consult the April 2005 comment of ISOC on the status of the Working Group on Internet Governance (WGIG) work in April 2005: 
"The Internet Society believes that the best way to extend the reach of the Internet is to build on those aspects that have worked well - e.g. the long established open, distributed, consensus based processes and many regional forums for the development and administration of the Internet infrastructure. Decision-making about issues such as resource allocation or IP Address Policy has always been in the hands of the Internet community, in order to be as close to those who require and use the resources as possible. It is this participative model, close to the end users, that led to the phenomenal, stable growth of the Internet." (...) "We want to encourage WGIG and WSIS to work with the Internet Community within the already well-established Internet model to improve co-operation between policy makers and the Internet community." [ISOC, 2005] In other words, let ISOC continue its work as before, without taking into account the recommendations of the WSIS for an improved cooperation between the different levels of governance and the multiple stakeholders!

There may be contradictions and surely tensions between the technical regulations and their coordination, and public policy issues [Klein, 2002]. Moreover, as stressed by L. Lessig, the possible architecture of Cyberspace are many: "the values that these architectures embed are different, and one type of difference is regulability - a difference in the ability to control behavior within a particular cyberspace. Some architectures make behavior more regulable; other architectures make behavior less regulable. These architectures are displacing architectures of liberty." [Lessig, 1999].

Above all, the point of view of ethics should question the normative character of technical regulation and its limits. It should also question the fact that some 4000 technical norms (RfC, for instance) are decided by only 2000 people and other few organizations without recognized legal status and then become universal norms?

\section{SELF-REGULATION}

\subsection{What is Self-Regulation?}

Pierre Trudel defines self-regulation as "resorting to voluntary norms developed and accepted by those that take part in an activity." [Trudel, 1989, 251] For Pierre Van Ommeslaghe, it is "a legal technique according to which rules of law or behaviour are created by the persons for whom they are 
destined to be applied, whether these persons design them themselves or whether they are represented to that end." [Van Ommeslaghe, 1995]

The self-regulation documents and the techniques used by it abound. They cover domains as diverse as the general governance of the Internet, the codes of ethics of societies of computer professionals, rules of behaviour and Netiquette of users of the networks, codes of conduct of access and service providers, rules of certification or labelling of websites; they are particularly developed in the electronic commerce sector in general, but also in the private sectors such as health, electronic publishing, software sales, telemarketing, and so on [IFIP-SIG9.2.2, 2000].

The names given to them is also diverse: charter, bills of rights, 10 or 12 commandments, principles, codes of ethics, codes of conduct, codes of practice, guidelines, standards, practices and uses, terms or contractual clauses.

The commitments vary from one to the next and, as we might assume from reading the names above, proposals relevant to pure ethics and codes of ethics are doubtless to be found, but also, more and more, simple commitments of an essentially contractual type defining services offered by companies and their clauses. The Internet users 'click' thus equates to the acceptance of these sorts of 'general contractual conditions'.

\subsection{Two Charters}

Two interesting French examples appear to us to show this difference: on one hand, the proposal of the French Internet Charter, put together in 1997, following the work of A. Beaussant, who was given the task by the Minister Francois Fillon_[French Internet Charter, 1997]; and on the other hand, the electronic publishing Charter (Le Monde, Libération, ZDNet, La Tribune, Investir, Les Echos, L'Agefi, France), published in 2000 [Electronic Publishing Charter, 2000].

The first one, which was no more than a proposal, was never adopted, in any case no more than the proposal put forward at the time by France at the OECD in the spirit of this Charter. It appeared, in fact, that the associations called to form the 'Internet Council' envisaged by the Charter never arrived at an agreement. The themes that they mentioned and about which signatories confronted each other were of interest to us at that time: protecting new spaces for expression and freedom with respect to everyone and in particular children; referring to the Charter on a site; adding a link to 
the Internet Council; supplying clear identification, banning all content or action manifestly contrary to public order and principally paedophilia, incitement to racial hatred, denial of crimes against humanity, incitement to murder, procuring, narcotics trafficking and procurement, attacks against national security; supplying parents with means to prevent sensitive material (ex. PICS, and so on); identifying pornographic and violent sites; defending freedoms and fundamental rights (freedom of expression, right to information, mail confidentiality, protection of private life, anonymity, and so on); protecting the intellectual property rights (patents, copyright...); defending the consumer (notably in electronic commerce): clarity of information about products, prices, conditions, the legal status of the vendor; protection against unsolicited advertising by email, honest and fair information; etc.

This charter, whose number of clauses are fairly typical of similar documents of current service providers in Europe [EuroIspa, 2005], might also be compared to the "Practices and uses" of the French Association of Providers of Access and Services (AFA), whose terms appear to us to be a retreat to the proposals of the Internet Charter [AFA, 2002]. They are also mentioned in the ethical dimensions of the Plan of Action of the 2003 WSIS. [WSIS, 2003, C10]

The electronic publishing Charter, another example, reaffirms the habitual rules of the profession and publishing rules that the publisher of a site attempts to respect scrupulously, but goes into the detail of the number of paragraphs that can be reproduced without being accused of plagiarism, defines what a 'short' citation is, gives the exact rules concerning the creation of links (authorized without conditions if the link opens a new browser window), banning, except with prior authorization, reproduction by means such as scanning, digital copying and so on.

This example allows us to appreciate that the word 'Charter' can have different meanings and that self-regulation, on the one hand, tends to define the rights and reciprocal duties of different Internet players, while, on the other, aspects of intellectual property by quickly define self-regulation more from a perspective of self-protection by a sector or company against practices that are harmful to them.

\subsection{Documents Related to Electronic Commerce}

Without going into too much detail, we should not miss out one of the most important fields in the development of self-regulation, notably 
electronic commerce. On this subject, we have to cite the efforts made firstly by the Electronic Commerce Platform Nederland (ECP-NL) and the Global Business Dialogue on Electronic Commerce (GBDe), and secondly by the European Commission in its eConfidence program [eCommerce, 2005]. These three initiatives stem from the belief that, if electronic commerce begins with difficulty, it is essentially due to a lack of confidence in the systems themselves and from the lack of legal protection.

ECP-NL is at the third version of what it calls a 'Model Code', which any company wishing to adhere to its principals can base itself, and thereby obtain a 'label of quality'. This code, negotiated with the consumer associations and representatives of companies under the guidance of the Minister of Economic Affairs, underlines the necessity of making commitments vis-à-vis the reliability of information, of systems and vis-àvis the organization, the transparency in communication, the rights to privacy, confidentiality of information and the rights to intellectual property. It seems to us that the measures of the ECP-NL offer little in addition to the law and do not offer added value to its effectiveness: all by showing the possibility and by supplying some examples of mechanisms in the explanatory notes, the document says that it supplies no clause model of enforcement.

The topics examined by the GBDe related to security, consumer confidence, the content of official communications, market access infrastructures, intellectual property rights, jurisdictions, responsibilities, protection of personal data and questions of taxation and tariffs. After its 2000 and subsequent Summits (Tokyo 2001, Brussels 2002, New York 2003, Kuala Lumpur 2004), these topics have been slightly redefined: consumer confidence, convergence, security, 'digital bridges' versus the 'digital divide', eGovernment, intellectual property rights, taxation, trustmarks, business and the World Trade Organization (WTO),...

In view of the abundance of initiatives of this type and, perhaps also, in view of the will of organizations that support them (GBDe was an initiative of some 60 big company chiefs of the calibre of America Online, Time Warner, Fujitsu, Vivendi Universal, Toshiba, Telekom Malaysia, Seagram, Eastman Kodak, Walt Disney, Hewlett Packard, IBM, MCI Worldcom, Alcatel, ABN AMRO Bank, DaimlerChrysler, and so on), the European Commission has been attempting to develop specific additional demands in its eConfidence program of general principles that would be applicable to all levels of online business, and furthermore, that would not be covered by the European legal clauses, but would be placed in the ensemble of European 
legal mechanisms relating to the consumer and to electronic commerce here it relates to a compilation of 'best practices', originating from the codes put together by the Commission working group, and, finally, principles designed to guide bodies towards official approval (the 'core group' assumes that the codes will be subject to official approval). The eConfidence Forum seems to us to be an interesting initiative to pursue, while being conscious that the current elaboration is being done by the work group.

It is a cause for celebration that the world of electronic commerce cares about a certain number of questions that otherwise stand a good chance of not finding a regulatory solution in the near future. The most important thing in this matter, for us, is to know who defines what and in the name of whom. It must be recognized that such initiatives are often born with the explicit concern of opposing governmental interference. The GBDe 'sherpas' call their annual 'Summit' the 'Davos of eCommerce'. And so be it; it is their right. We can, however, question the absence of real dialogue and participation of people who "take part in activities" (we are referring here to the Pierre Trudel's definition) who define electronic commerce. One cannot avoid the impression that many current codes, in their present form, hardly express more than idealistic principles that, too often, are not even accompanied by sanctions or indictment procedures in the case of disputes.

Without doubt, a number of questions related to our ethical preoccupation cross our minds that we can merely list here: What forms, or what techniques does self-regulation cover? Codes? Labelling? What is its place in the legal pluralism and the normative order? Is it a complement to the law, its substitute or an anticipation? With regards to democratic order, what is its legitimacy, how representative is it in its elaboration? What are the social acceptance places? What is at stake? Are there not any areas that should escape self-regulation in the name of other principles, for example democratic or ethical principals? [Berleur, 1999] What protection for citizens and democracy do we have the right to expect from regulators? What is the constraining legal force, what are planned sanctions and procedures to resolve disputes? Is there no place, in the final analysis, to define a legal framework according to the usual democratic criteria, and again at the international level - what permits the development of instruments of self-regulation to genuinely give people confidence, because they are implicated one way or another?

It is perhaps still too early to give a satisfactory answer to these questions, but they must surely be kept in mind and worked on. States, as 
much as consumer associations, should be more involved in places where such regulatory tools are being prepared.

One thing that has seemed of utmost importance, that we have read on the GBDe site, is that the GBDe, the International Chamber of Commerce (ICC) and the Business and Industry Advisory Committee (BIAC) with the OECD signed an agreement on the problems of electronic commerce on $13^{\text {th }}$ December 2000: "the GBDe, the ICC and the BIAC are working together to further their international cooperation in all areas of general politics linked to the Internet (on the full range of public policy issues arising from the Internet; we highlight)."

We cannot hide our surprise when looking at the follow up that has been given to the 1997 "Green paper on the protection of minors and human dignity" [Green Paper, 1997]. Measures which have been taken can be read as reinforcing the responsibility of the people on the 'front line' - and that is surely positive, but also as leaving to the 'market' matters which, at least partially, should traditionally depend on the judicial order. Who, for instance, will decide of the 'illegal' or 'harmful' character of the Internet content? Who does the classification? What kind of classification scheme is used? [Resnick, 1999] Self-regulation in this matter is, in our view, a choice allowing the content providers as well as the service providers to establish the minimal rules.

The concept of co-regulation has been advanced by the summit of regulators in 1999, which was convened under that aegis of the Audiovisual High Council (CSA, Conseil Supérieur de l'Audiovisuel), and of UNESCO. Michel Vivant, in his conclusion, preferred the term multi-regulation or 'plural regulation'. It is this movement that we are referring to here. In truth, co-regulation can take different senses according to, as numerous commentators highlighted at the creation of the GBDe, it relates or does not relate to curbing intervention by public authority (Associated Press) and the creation of a sort of 'Net Parliament' (L'Express) or, on the contrary to 'setting up watchdog, dialogue and mobilization authorities', as Madame Falque-Pierrotin, the President of the Internet Rights Forum (Forum des Droits de l'Internet), said. The role of the law will allow us to define our approach more precisely.

Abruptly said: the slogans of self-regulation, 'The least State possible is the best', 'Let us avoid a greater degree of statutory regulation', or 'Let business self-regulate the Net' belong to the 'knee-jerk antigovernment rhetoric of our past", and cannot persist without damage for a democratic 
society [Lessig, 1999]. Does the ubiquity of ICT allow us to leave the choices about the future of our societies and enterprises to the sole forces of market or of lobbies? The State has not to rule everything, sure. But it must define as clearly as possible, and in a transparent manner, the principles and the values that it wants to be respected. Where are the places of dialogue and of early warning?

If self-regulation must reflect ethical concerns, then there would be minimum requirements to be met. IFIP-SIG9.2.2 has expressed its concerns about that and made some recommendations [IFIP-SIG9.2.2, 2004]. A recent initiative of the European Commission aiming at developing a methodology for assisting self-regulatory bodies to implement codes of conduct within/across the various media sectors in Europe goes along the same line.

From a strict ethical point of view, let us make the following comments or raise certain questions: we should request more professionalism from professional bodies, i.e. clearer statements on issues in specialized fields where they develop their competence; anticipate threats and dangers; increase international exchange between professional societies and institutional groups, respecting the cultural, social, and legal differences; reflect on the "shift from deontology for informaticians to a deontology of informatics under the control of the law" (Herbert Maisl); question selfregulation in terms of improvement of commitment and responsibility of organizations - is it not too minimalist? Increase self-regulation legitimacy by promoting large participation of all the concerned parties; refrain from slogans of the past, such as "Let business self-regulate the Net" which are at risk of damaging societal fabric, and which are not favouring the cooperation between private and public; clarify the relationship between deontology, self-regulation, the law, and ethics.

Some last ethical important questions: self-regulation is trying to find its place in the normative order, but doesn't it still remain, from the content point of view, minimal if not minimalist? One of the main questions: the normative role of private actors. What should be the role of the regulators to protect citizen and customers? The signs of real participation of the actors are rare: where is democracy? Is self-regulation making the actors more responsible? 


\section{LEGAL REGULATIONS}

Among Internet regulators, certain authors have, doubtless too quickly, described the legislator as too slow, too unqualified, and too national to frame such a mobile, technical and global reality as cyberspace. They were ill-advised. Some authors have opposed criticisms and proposed alternatives [Trudel 1996, 137], [Lessig, 1999], [Poullet, 2000]. Europe, in particular, issues repeated directives on this subject and, in an area where the United States is refusing to legislate, like data protection, a body as official as the Federal Trade Commission (FTC) pleaded recently for a legislative initiative in the area of protection of privacy on the Internet [FTC, 2000]. How can this phenomenon be explained? A single word: confidence. It is clear that the difficulties that are increasingly resented by the electronic commerce sector for example, can be explained by the absence of confidence by Internet users as much in network security and transactions that build up, as in the possibility, in the case of dispute, to be able to clearly identify the legal frame of reference to bring about a solution and take exact decisions [European Parliament, 2000].

In general, the law undeniably has a reassuring function in this respect. It creates a clear frame of reference, subjugates players to stipulations that guarantee security, fairness and a good outcome. Moreover, it gives the public power teeth for complaints by those who are at risk on the web. Doubtless, its territorial limits are questioned at a time of the global network of networks, but the construction of regional legal spaces like the European Union and the increasingly numerous discussions at the heart of supranational official bodies like the OECD, WIPO, WTO, the Council of Europe, and so on, allow the progressive establishment of adequate regulatory consensus [Trudel, 1995].

That said, it is perhaps useful to consider the areas of intervention by the legislator and to study its goals in the various areas. It is about, they say, building confidence, but in what and in favour of whom?

We will limit our analysis to a comparison of the European and American interventions.

The first area of legal intervention is undeniably that of intellectual property and related rights. As the Bangemann report noted, it is about protecting the agreed investments by those that tomorrow will become the service providers of the information society. This political will to protect the investment translates into laws which, very often, neglect to take into 
consideration the balances written into the heart of traditional legislation on copyright. Whatever happened to exceptions about private copying, copying for educational, research or critical purposes, and so on, that became simply optional according to the recent 2001 European directive on copyright and related rights [European Commission, 2001]? Following the example of the 1998 US Digital Copyright clauses, the law protects technical measures that permit the restriction of access to information, even when this is not entitled to legal protection. Furthermore, they institute - this is at least what the 1996 European directive on databases decided - protection of data compilations, even those that are not protected by copyright by inventing a right sui generis to protection [European Commission, 1996].

Protecting investors guarantees the presence of content on the Internet. Then, secondly, transactions still have to be developed, be it transactions between professionals ( $\mathrm{B}$ to $\mathrm{B}$ ) or with consumers ( $\mathrm{B}$ to $\mathrm{C}$ ). To do this, the issue is one of reassuring about the identity of the partners in a transaction, about the authentication of messages and the assurance of confidentiality. The legislation, adopted as much by one side of the Atlantic as by the other on the subject of electronic signatures, granting them the same value as written signatures and granting electronic documents the same value as written ones, answers this first concern [European Commission, 1999]. The failure of electronic B to C commerce has led Europe to answer the Internet users' fears through legislative initiatives. The directive on electronic commerce adopted in June 2000 had two goals. On the one hand, to oblige member states to brush away their legal arsenals by repealing all legal constraints that could deprive electronic transactions (e.g. formal rules based on paper documents) of validity or efficacy. There, it plays a role of promoting electronic commerce. On the other hand, it plans new requirements about transparency of service providers and the sequence of transactions in various stages by way of assuring the complete and conscious consent of the Internet user [European Commission, 2000].

The protection of investments and transactions on the Internet equally demands the possibility of detecting illicit schemes on the Internet and of efficiently punishing their perpetrators. That was the third common legislative measure. The attention drawn to the crime of paedophiles on the Internet and other actions against human dignity, like xenophobic or racist messages, has brought legislators, with the support of public opinion, to largely define computer crime (in certain countries, the simple fact of having accessed a site, without even having any fraudulent intent, is punishable), to considerably extend the means of investigating policing authorities by giving them the right to search using the networks, by obliging private providers 
(i.e. access providers) to keep data about usage of their services and to cooperate with the authorities and finally, by promoting international police cooperation. We could talk about transforming them into genuine representatives of the law. Under American pressure, the Council of Europe adopted an international convention on cybercrime in December 2000 that conveys the whole of these tendencies and allows effective cybersurveillance of the actions of everyone on the web [Council of Europe, 2000]. In this field, the principles of freedom of expression and the protection of privacy were too quickly forgotten, although these were the principles, which the Council of Europe had previously demanded absolute protection of at its founding convention.

It is precisely with respect to the last topic, the protection of freedom, that legal intervention should be analysed. Freedom of expression is certainly one of the founding dogmas of the Internet. Certain people even said that self-regulation would be a compromise to maintain the Internet's spirit of freedom. The question of the abuses of this freedom (illicit or prejudicial messages) has been envisaged, away from the question of punishment of their perpetrators, by a system of exoneration of responsibilities of intermediaries regarding surveillance of information that it gives access to [Montero, 2000]. It is about avoiding every preventative measure that could take these intermediaries who, to avoid being investigated, would censor the content of information that they give access to. For the rest, freedom of expression on the Internet is considered a given considering the low cost of having a network presence and the potential global access of the content of sites. Organizations like UNESCO are frequently reminded that such access was not as straightforward for everyone, so that there is room to encourage not just the pluralism but also the cultural diversity and geographical origin of messages to be seen on the network, and not to be content with a pure and simple application of competition laws [UNESCO, 2000]. Furthermore, the United States more than Europe had defined a legislative policy of universal access to infrastructures for all (right to electronic signature, right to email and so on) but equally to certain content judged to be essential in an information society [de Terwangne, 2001]. Is this right of access not effectively the condition of the participation of everyone in the information society and therefore of their freedom of expression?

From the legal regulations point of view, the question of the protection of personal data still appears to be the one that most profoundly divides the United States and Europe. Even considering the greater sensitivity of American Internet users than Europeans, the United States refuses every 
initiative on this subject, where Europe attempts to sharply adapt its regular demands to answer the challenges set by new technologies. Thus Europe has recently produced a directive [European Commission, 2002] that limits the use of traffic and location data, subjects the sending of emails to consent and reserves the right for the Commission to use technical standards to combat 'privaticides': technologies such as cookies, invisible hyperlinks, and so on [Dinant, 1999]. The demand for adequate protection to be offered by third countries in the case of flows across frontiers has led Europe to get the United States to adopt the 'Safe Harbor Principles', a self-regulatory system that offers certain protection for European personal data, that the Commission deems adequate [Poullet, 2000b]. We know that the new American administration has attempted to change the Commission's decision, but to date unsuccessfully.

\section{CONCLUSION}

The hierarchy in the field of protection that is ensured by the law reveals the values of the societies that give rise to those laws. To the American authors denying the need for laws to regulate cyberspace, we retort that the Americans were the first to intensively legislate in the field of intellectual property and new technologies, and that only certain questions like the protection of privacy or limits on freedom of expression are currently left in the realm of self-regulation.

The European legal approach to the other means of regulation deserves to be underlined. If technical regulation and self-regulation are promoted, it is under the control or in any case, within the framework and control - the word is perhaps too strong - of public authorities. Recent European and worldwide interventions in the field of 'governance' of the Internet have demonstrated this tendency well. Through various documents, the European Parliament and the European Commission as well as, now, the World Summit on Information Society through notably its Working Group on Internet Governance have insisted on the need to play a leading role in the functioning and decision making of organizations such as ICANN, the need for a better regional balance in its leadership bodies, and above all of the recognition of the system of domain names as a public resource, in accordance with intellectual property rights, competition and the protection of data and representative of the world's cultural and linguistic diversity [Delmas, 2001], [Froomkin, 2000]. However, it appears that the US Government is not ready to leave to others the control of an organization that it has accepted to be "private under control"! (U.S. Statement of Principles, 
http://www.ntia.doc.gov/ntiahome/domainname/USDNSprinciples_0630200 5.htm)

The European Commission's proposal to be able to intervene in the field of technical standardization with the aim of ensuring the respect of principles of protection of personal data, during Internet use is equally indicative of the tendency to more control. It is clear that the public authorities cannot remain absent from technical debates where the choices made have a profound impact on the rights and freedoms of users of those technologies. Accordingly, all self-regulation is subject to certain conditions through the texts of the European Directives [Poullet, 2000c]. The importance of the participation of all interested actors has already been insisted upon here, a point which a number of European texts highlight. Self-regulation, far from being a substitute for regulation appears more like its complement, offering a real additional value. Thus, the more or less voluntary systems of official approval, enforced to give a 'legal' label to self-regulation initiatives, are multiplying. Lastly, the need for effective self-regulation must be insisted upon and if it is to be applied by private judges or mediators, then should respect certain procedural rules through certain guarantees concerning the judges or mediators. Cybercourts and cyberjudges must be legally founded.

It is beyond doubt that the law has a good future, even in Cyberspace. If, as everyone delights in saying, information technology increasingly governs our behaviour, determines the life of our companies, and the future of our societies, there will be no question of leaving such choices to the discretion of market forces or lobbies. This indicates the place and the role of the State. For the State, it is not about regulating but about fixing the principles and social values that it intends to see respected in a clear and transparent way. It is about, above all, constructing places for dialogue, watch and observation, where all interested actors can compare their points of view, analyse the technical and self-regulatory solutions and suggest up to and including legal actions if necessary [Reidenberg, 1996]. If the law has no more than a secondary role, then this role is at the same time fundamental because it represents the basic consensus from which the other regulatory instruments could define themselves. Should this basic consensus be sought at the international level, as the global dimension of the Internet demands? We do not think so. Even as a 'web citizen', the Internet user remains a citizen attached to his or her values and to his or her local culture [Rodota, 2000]. The reality of cyberspace doubtless opens itself to other cultures and values more and more each day and therefore begs the search for consensus that is no longer local, nor national, but rather at the regional or world level. If such a direction is to be followed however, it should not be at the expense of a 
renunciation of the values nor by defining smaller common denominators or at the cost of solutions imposed by the market.

The role of ethics is to keep open an horizon of universality, or to avoid the appropriation of the norms by anybody, be they technical or selfregulatory. This is a must if there are vested interests which do not respect the balance through appropriate levels of democratic discussion. Regulation is multidimensional and must find its coherence and consistence. Today it is still a "battlefield".

\section{REFERENCES}

Abramatic, 2005. Jean-François Abramatic, About the World Wide Web Consortium (W3C), http://www.w3.org/Consortiun/

AFA, 2002. Association des Fournisseurs d'Accès et de Services, Pratiques et Usages, Mise à jour septembre 2002, http://www.afa-france.com/deontologie.html

Berleur, 1999. We have proposed a simple rule inspired by the Kantian deontological tradition: "As soon as the interest of the majority are at stake and that people concerned risk to be made more fragile and vulnerable, the public authority must interfere and ensure that an 'horizon of universality' remains open." See: Jacques Berleur, Self-Regulation and Democracy: Choice and Limits?, in: User Identification \& Privacy Protection, Applications in Public Administration \& Electronic Commerce, Simone Fischer-Hübner, G. S., Quirchmayr \& Louise Yngström, Eds., Dept of Computer and Systems Sciences, Stockholm University/Royal Institute of Technology, Report Series 99-007, 1999, ISBN 91-7153-909-3, pp. 1-19.

Brousseau, 2001. Eric Brousseau, Régulation de l'Internet : l'autorégulation nécessite-t-elle un cadre institutionnel ?, in : E. Brousseau and N. Curien, (éds.), Economie de l'Internet, Revue Economique, Numéro spécial, Septembre 2001.

Cerf, 1999. Vinton Cerf, On the Internet, July-August, 1999.

Council of Europe, 2000. The text of the Convention $n^{\circ} 185$ on Cybercrime is available on the site of the Council of Europe http://conventions.coe.int/Treaty/FR/cadreprojets.htm

de Terwangne, 2001. Cécile de Terwangne, La mission publique de l'Etat dans la Société de l'Information, Brussels - Bruylant, 2001.

Delmas, 2001. Richard Delmas, L'Internet et les chantiers législatifs européens, in : L'Internet et le droit, Actes du colloque de l'Université de Paris 1, 25 et $26^{\text {th }}$ September 2000, Legipresse, 2001

Froomkin, 2000. M. Froomkin, Lessons learned from the WIPO domain name process, Regulating the Global Information Society, C.T. Marsden (ed.), Routledge, London - New York, 2000, p. 210 et sv.

Dinant, 1999. Jean-Marc Dinant, Les traitements invisibles sur Internet, in: Droit des technologies de l'information - Regards prospectifs, in Cahiers $d u C R I D, \mathrm{n}^{\circ} 16$, Brussels Bruylant, 1999, p.287 sv.

eCommerce, 2005. http://www.ecp.nl, http://www.gbde.org, http://econfidence.irc.it

Electronic Publishing Charter, 2000. Charte d'édition électronique http://www.liberation.fr/licence/charte.html

EuroIspa, 2005., European Internet Services Providers Association, Pages detailing the Codes of Conduct for members of EuroISPA, http://www.euroispa.org $/ 25$, htm 
European Commission, 1996. Directive of $11^{\text {th }}$ March 1996 on the legal protection of databases, O.J.E.C, 27 March 1996, L077/20.

European Commission, 1999. Directive 1999/93/EC of the European Parliament and of the Council of 13 December 1999 on a Community framework for electronic signatures, O.J.E.C., $19^{\text {th }}$ January 2000, L013/12.

European Commission, 2000. Directive 2000/31/EC of the European Parliament and of the Council of 8 June 2000 on certain legal aspects of information society services, in particular electronic commerce, in the Internal Market Directive on electronic commerce, O.J.E.C., L178, 17/07/2000 pp. $01-16$.

European Commission, 2001. Directive 2001/29/EC of the European Parliament and of the Council of 22 May 2001 on the harmonisation of certain aspects of copyright and related rights in the information society, O.J.E.C., $22^{\text {nd }}$ June 2001, L167/10.

European Commission, 2002. Directive 2002/58/EC of the European Parliament and of the Council of 12 July 2002 concerning the processing of personal data and the protection of privacy in the electronic communications sector - Directive on privacy and electronic communications, O.J.E.C., L201, 31/07/2002, pp. $37-47$.

European Parliament, 2000. Advice of the Economic and Social Committee of the European Parliament on the 'Effects of electronic commerce on the single market (SMO)' of the $2^{\text {nd }}$ March 2000, O.J.E.C on the $25^{\text {th }}$ April 2001, C 123/1.

French Internet Charter, 1997. http://www.planete.net/code-internet/ The access to this site is possible through $h t t p: / / w w w$. archive.org

FTC, 2000. Statement given by the Federal Trade Commission on $25^{\text {th }}$ May 2000 before a Senate committee: Privacy Online: Fair Information Practices in the Electronic Marketplace, http://www.ftc.gov/os/2000/05/testimonyprivacy.htm

Green Paper 1997. European Commission: 'Green paper on the protection of minors and human dignity in audiovisual and information services', COM (97) 570 final, 18.11.1997. This text and its following recommendations, decisions or actions are available at http://europa.eu.int/comm/avpolicy/regul/new srv/pmhd en.htm

ICANN, 2002. President's Report: ICANN - The Case for Reform, 24 February 2002, http://www.icann.org/general/lynn-reform-proposal-24feb02.htm See also the discussion: Committee on ICANN Evolution and Reform Seeks Public Submissions, 27 March 2002 ; ICANN Board Accepts Contributions to Facilitate At-Large Organizing Efforts, 24 April 2002; Working Paper on ICANN Mission and Core Values, 6 May 2002, http:/www.icann.org/committees/evol-reform/working-paper-mission-06may02.htm, ...

Klein \& Mueller, 2005. Hans Klein \& Milton Mueller, The Internet Governance Project, April 5, 2005: What to do about ICANN, A proposal for Structural Reform, http://www.internetgovernance.org/)

IFIP-SIG9.2.2, 2000. Jacques Berleur, Penny Duquenoy, Marie d'Udekem-Gevers, Tanguy Ewbank de Wespin, Matt Jones and Diane Whitehouse, Self-Regulation Instruments Classification - A Preliminary Inventory, (HCC-5, Geneva 1998; SIG9.2.2 January 2000; SIG9.2.2 June 2000; IFIP-WCC-SEC2000), http://www.info.fundp.ac.be/ ibl/IFIP/sig922/selfreg.html Other 'Internet Resources on Self-Regulation and the Internet' can also be found on one of the site of the Law Faculty of the University of Washington at http://www.law.washington.edu/lct/publications.html

IFIP-SIG9.2.2, 2004. Criteria and Procedures for Developing Codes of Ethics or of Conduct. To Promote Discussion Inside the IFIP National Societies. On behalf of IFIP-SIG9.2.2: Jacques Berleur, Penny Duquenoy, Jan Holvast, Matt Jones, Kai Kimppa, Richard Sizer, and Diane Whitehouse, Laxenburg, IFIP Press 2004, ISBN 3-901882-19-7 http://www.info.fundp.ac.be/ jbl/IFIP/Criteria and procedures.pdf 
ISOC, 2005. ISOC Commentary on the status of the work of the Working Group on Internet Governance, April 2005, http://www.isoc.org/isoc/conferences/wsis/

Klein, 2002. Hans Klein, ICANN and Internet Governance: Leveraging Technical Coordination to Realize Global Public Policy, The Information Society - An International Journal (Taylor and Francis, ed.), vol. 18, n³, 2002, pp.193-207.

Lawton, 2001. George Lawton, Is IPv6 Finally Gaining Ground, in: Computer, IEEE Computer Society, August 2001, pp. 11-15.

Lessig, 1999. Lawrence Lessig, Code and Other Laws of Cyberspace, Basic Books 1999.

McCullagh, 2005. Declan McCullagh, U.S. to retain control of Internet domain names, $\mathrm{New}$ York Times, July 1, 2005

Montero, 2000. Etienne Montero, La responsabilité des prestataires intermédiaires de l'Internet, Rev. Ubiquité, June 2000, n5.

On the Internet, 2001. On the Internet, Spring/Summer 2001, pp. 13, 26.

PICS. There are numerous sites about PICS. First, the official one of W3C : Platform for Internet Content Selection, http:/www.w3.org/PICS/; the papers of Lorrie Faith Cranor, Paul Resnick, and Danielle Gallo, A Catalog of Tools that Support Parents' Ability to Choose Online Content Appropriate for their Children, http://www.research.att.com/ lorrie/pubs/tech4kids/; the web site of 'Computer Professionals for Social Responsibility' and its specific page 'Filtering FAQ' in particular the question on PICS at http://www.cpsr.org/filters/faq.html, etc.

Poullet 2000. Yves Poullet, How to regulate the Internet: New paradigms for Internet Governance, E-Commerce Law and Practice in Europe, I. Walden - J. Hörnle (éd.), Woodehead, Cambridge, 2000, Section 1. Chapter 2.

Poullet, 2000b. Yves Poullet, Les Safe Harbor Principles : Une protection adequate?, published at http://www.droit-technologie.org in the column : Dossiers, 10.07.2000.

Poullet, 2000c. Yves Poullet, Les diverses techniques de réglementation d'Internet: l'autorégulation et le rôle du droit étatique, Rev. Ubiquité, n 5 , Juin 2000, p. 55 et sv.

Quéau, 1999. Philippe Quéau, Internet: vers une régulation mondiale, Sommet mondial des régulateurs sur Internet, CSA - UNESCO, Paris, $30^{\text {th }}$ November - 1st December 1999, http://www.unesco.org/webworld/news/991201 queau csa.shtml

Regulating the Internet, 2000. Regulating the Internet - The Consensus Machine, in: The Economist, June $10^{\text {th }}, 2000$, pp. 99 sv.

Reidenberg, 1996. Joël Reidenberg, Governing Networks and Cyberspace Rule Making, Emory Law Journal, 1996., p. 911 ff.

Reidenberg, 1998., Joël Reidenberg, Lex Informatica: The Formulation of Information Policy Rules through Technology, in: 76 Texas L. Rev. 553-584 (1998)

RfC, 2005., IETF, Request for Comments Index, http://www.ietf.org/iesg/1rfc index.txt

Resnick, 1999. Paul Resnick, PICS, Censorship, and Intellectual Freedom FAQ, http://www.w3.org/PICS/PICS-FAQ-980126.html and the PICS sites we mentioned under PICS.

Rodota, 2000., We owe this reflection to S. Rodota, president of the Group called Article 29, made up of representatives of the data protection authorities who defended this idea in the conclusion of 22 nd international symposium of data protection ombudsmen, organised by the Italian Garante in Venice (September 2000)

Simonelis, 2005. Alex Simonelis, A Concise Guide to the Major Internet Bodies, in: Ubiquity, Views, Issue 5, February 16-22, 2005, http://www.acm.org

Standards, 2001. The Standards Issue, On the Internet, Spring/Summer 2001.

Trudel, 1989. Pierre Trudel, Les effets juridiques de l'autoréglementation, in : Revue de droit de l'université de Sherbrooke, 1989, vol. 19, n² 2 .

Trudel 1995. Pierre Trudel (ed.), Le droit du cyberespace, Thémis, 1995. 
Trudel 1996. Pierre Trudel, Le cyberespace, réseaux constituants et réseau de réseaux, in : Les autoroutes de l'information: enjeux et défis, Actes du colloque Jacques Cartier, Lyon, 1996

UNESCO, 2000. Conclusions of the $3^{\text {rd }}$ InfoEthics Congress (UNESCO, November 2000).

Van Ommeslaghe, 1995. Pierre Van Ommeslaghe, L'autorégulation. Rapport de synthèse, in: L'autorégulation, Bruxelles, Ed. Bruylant, 1995, pp. 233-274.

WGIG, 2005., Working Group on the Internet Governance, http://www.wgig.org

WSIS, 2003. Declaration of Principles, World Summit on the Information Society, First Phase, Geneva 2003, see in particular nr. $48 \& 50$, http://www.itu.int/wsis. See also the Plan of action nr. 13b, and C10, nr. 25, as well as the Civil Society Declaration Shaping Information Societies for Human Needs. 